\title{
REPRESENTAÇÕES NA MÍDIA DA JUVENTUDE E A PRODUÇÃO DO MEDO: EXPERIÊNCIA EM UMA CIDADE MÉDIA BRASILEIRA ${ }^{\mathrm{i}}$
}

\author{
ClaAice CASSAB ${ }^{1}$ \\ Juliana Aparecida Cantarino Toledo ${ }^{2}$ \\ Kátia Oliveira Ferreira ${ }^{2}$ \\ Rayssa Pinto Rezende ${ }^{2}$
}

\begin{abstract}
RESUMO - A cidade pode ser o locus da experiência política. Para tanto, é central que ela possa ser apropriada através do seu uso. Contudo, o que se nota é que cada vez mais o medo e a insegurança têm restringido seu uso mediante a determinação dos lugares e dos sujeitos violentos. O objectivo deste texto é discutir a forma pela qual são construídas as imagens dos jovens pobres e de seus bairros periféricos a partir da imprensa e ainda compreender como a mídia contribui para a elaboração de uma representação social que, além de produzir uma imagem estereotipada daqueles jovens e de seus bairros, restringe as possibilidades de mobilidade pela cidade. $O$ trabalho é fruto de pesquisa realizada num jornal local, para sua realização foram coletadas matérias envolvendo jovens no período de 2005 a 2011 na cidade de Juiz de Fora, Brasil. Em seguida, foram realizadas entrevistas com jovens estudantes da cidade, com o intuito de cotejar suas escolhas em relação aos locais que evitam frequentar e as representações sociais da violência. O que se nota é a forte associação entre as imagens difundidas pela mídia e as escolhas relativas aos lugares da cidade que os jovens estudantes evitam.
\end{abstract}

Palavras-chave: Juventude; cidade; mídia; representação social.

ABSTRACT - REPRESENTATIONS OF YOUTH IN THE MEDIA AND THE PRODUCTION OF FEAR: EXPERIENCE IN AVERAGE CITY IN BRAZIL. The city can be the locus of political experience. However, it is eminent that increasing fear and insecurity has restricted its use through the determination of violent places and subjects. The purpose of the paper is to discuss how images of poor youth and their suburbs are constructed by the media. The objective is to

Recebido: Junho 2014. Aceite: Abril 2016.

1 Docente da Universidade Federal de Juiz de Fora, Departamento de Geociências, 36037-087, Rua Ervália 28 - casa 1, São Pedro Juiz de Fora - MG, Brasil. E-mail: clarice.torres@uff.edu.br

2 Universidade Federal de Juiz de Fora, Departamento de Geociências, 36037-087, São Pedro Juiz de Fora - MG, Brasil. E-mail: Juliana_cantarino@yahoo.com.br; katiaferreira2312@gmail.com; rayssarezende@yahoo.com.br 
comprehend how the media contributes to the development of social representation that, besides producing a stereotyped image of those young people and their neighborhoods, restricts the possibilities of mobility throughout the city. The work is the result of research conducted at a local newspaper. Material was collected involving young people over the period between 2005 and 2011 in the city of Juiz de Fora, Brazil. Then interviews were conducted with young students from the city in order to collate their choices related to places they avoid frequenting and the social representations of violence. There is a strong association between the images broadcast by the media and the choices relating to places in the city that the young students avoid.

Keywords: Youth; city; media; social representation.

RÉSUMÉ - REPRESENTATION MEDIATIQUe DE LA JEUNESSE ET DE LA NAISSANCE DE LA PeUr. L'exemple D'Une ville Brésilienne moyenne. L'expérience politique peut être acquise en ville, à condition de connaitre bien celle-ci. Or, on remarque que cette connaissance est de plus en plus limitée, à cause de l'insécurité et de la peur liées aux lieux et aux gens considérés comme violents, on discute ici la façon dont sont construites par la presse les images de la jeunesse défavorisée et des quartiers périphériques, afin de comprendre comment les médias contribuent à l'élaboration d'une représentation sociale qui, en produisant des images stéréotypées, restreint les possibilités de circulation à travers la ville. Cette étude résulte d'une recherche réalisée en rassemblant sur un journal de la ville brésilienne de Juiz de Fora, de 2005 à 2011, les informations concernant les jeunes et en réalisant des entrevues avec des étudiants afin de déterminer leurs choix concernant les lieux fréquentés ainsi que leur représentation sociale de la violence. On note une forte corrélation entre les images diffusées par les médias et les lieux évités par les étudiants en raison de leur violence.

Mots clés: Jeunesse, ville, médias, représentation sociale.

\section{INTRODUÇÃO}

O texto discute como são construídas as imagens dos jovens pobres a partir da mídia e de que maneira ela contribui para a construção de uma representação social que, além de produzir uma imagem negativa desses jovens e de seus bairros, restringe as possibilidades de mobilidade pela cidade ao forjar a sensação de medo e de insegurança.

Tratar juventude como categoria social significa pensá-la como uma representação sociocultural e uma situação social. A juventude é uma percepção simbólica produzida pelos próprios sujeitos, tidos como jovens e pelos grupos sociais que compõem a sociedade. Os jovens, inseridos em processos sociais complexos, experimentam a juventude de acordo com os espaços, tempos e contextos em que vivem. Por essa razão, é possível afirmar que não existe apenas um tipo de juventude, mas juventudes, que assumem diferentes expressões de acordo com as condições culturais e materiais que as rodeiam. Cada juventude, portanto, deve ser entendida a partir de suas experiências individuais e coletivas. Cada jovem se assemelha ou se distingue um do outro de acordo com suas afinidades de valores, seu modo de vida em comum e pelas estratégias de enfrentamento da vida cotidiana que se entrelaçam ao ambiente urbano. Destaca-se, portanto, que a juven- 
tude é um momento da vida que se define em um determinado contexto histórico e geográfico. Ela não é uma entidade de espírito como se difunde, por exemplo, nas representações midiáticas que estimulam o consumo a partir de um comportamento associado à juventude, assim como não deve ser concebida a partir de esquemas modulares, ou tipologias homogeneizantes. Por fim, certamente não se refere a um período de transição entre a dependência da infância e a independência da vida adulta. Castro e Abramovay (2003: 15), são enfáticas ao afirmarem que "definir juventude implica muito mais do que cortes cronológicos, implica vivências e oportunidades em uma série de relações sociais, como trabalho, educação, comunicação, participação, consumo, gênero, raça etc". Desse modo, embora o corte cronológico seja importante para a delimitação metodológica dos sujeitos dessa pesquisa ele não é o que define os jovens estudados. Contudo, se cada juventude deve ser entendida a partir de suas experiências individuais e coletivas é fundamental delimitá-la. No trabalho, o corte cronológico de 14 a 24 anos, adotado pelo Instituto Brasileiro de Geografia e Estatística (IBGE), aparece como suporte na delimitação do universo sem, no entanto, ser o marco definidor dos sujeitos dessa pesquisa. Aqui, os jovens serão apresentados e definidos a partir de duas vivências distintas. A primeira aquela marcada pela pobreza. Nesse caso, a pobreza refere-se a distintas formas de privação de bens materiais e simbólicos fundamentais para a vida. Tratada não apenas como uma categoria econômica ou política, mas como algo que está presente na própria produção da subjetividade dos indivíduos e sendo capaz de situar esse sujeito na sociedade a qual pertence e a própria pobreza como um fenômeno que afeta os sujeitos como um todo. Jovem pobre é adotado no sentido de refletir um corte dentro do universo da juventude e refere-se àqueles que vivem uma juventude marcada fortemente pelos processos de desigualdade social e de distinção territorial. São aqueles jovens que pouco vivem os direitos sociais sendo também estigmatizados em função dos seus lugares de moradia. São aqueles retratados pelas notícias difundidas no jornal pesquisado. A segunda vivência refere-se aquela partilhada pelos jovens estudantes entrevistados na pesquisa e que os colocam num lugar diferenciado em relação aos noticiados na imprensa, em função de um conjunto de oportunidades que passa pela família, pela educação e pelo emprego.

Ambos têm em Juiz de Fora o espaço onde se definirá e se desenrolará suas juventudes. O município de Juiz de Fora integra a microrregião de mesmo nome e a mesorregião da Zona da Mata Mineira, na região Sudeste brasileira. De forma geral, é possível dizer que seu desenvolvimento está fortemente vinculado aos fluxos de pessoas, capital, serviços, de três das grandes metrópoles brasileiras: Rio de Janeiro, Belo Horizonte e São Paulo. Sua posição geográfica possibilitou que o município e, em particular, a cidade de Juiz de Fora, adquirisse certa centralidade na região, cumprindo o papel de conexão entre pequenos centros urbanos e rurais e as grandes cidades.

Conforme o último censo de 2010, Juiz de Fora possui 516247 habitantes, sendo que 87790 encontravam-se na faixa de 15 a 24 anos. O que corresponde a $17 \%$ da população total. Da população total de jovens $99 \%$ vive na área urbana, sendo que 43285 são homens e 43649 mulheres. Atualmente, a população estimada pelo Instituto Brasileiro de Geografia e Estatística (IBGE) é de 550710 habitantes. 
Em relação aos demais municípios da sua microrregião, Juiz de Fora responde por $70,8 \%$ da população total e por $23,7 \%$ dos moradores da mesorregião Zona da Mata. A população de Juiz de Fora aumentou 13,3\% nos últimos dez anos, correspondendo ao $4^{\circ}$ município do estado de Minas Gerais em número de habitantes, tendo um aumento maior do que o registrado em todo o estado $(9,52 \%)$.

Juiz de Fora se configura como o principal pólo regional da Zona da Mata, sendo o $5^{\circ}$ município do estado no setor de serviços e o $10^{\circ}$ no setor industrial. Tem-se observado, nos últimos anos, o crescimento de oferta de serviços de ponta e comércio, convertendo a função urbana da cidade rumo a um setor terciário especializado, em que se destacam os serviços privados, como modernos procedimentos médicos e variadas atividades educacionais. São essas actividades as que mais têm aumentado na cidade, ampliando a oferta que visa atender a demanda não apenas da microrregião, como também de muitos municípios da Zona da Mata Mineira e mesmo da região Serrana do estado do Rio de Janeiro e cidades do Vale do Paraíba - RJ. A breve caracterização permite inferir o peso de Juiz de Fora na região, o que tem impulsionado um importante crescimento demográfico e econômico do município.

Do ponto de vista de sua urbanização é possível afirmar que ela se deu pela lógica clássica da expansão "em salto", na qual vazios urbanos são mantidos como reservas especulativas e tendo seu valor ampliado a partir da implantação da infraestrutura básica. É assim que, a partir das décadas de 1960-1970 a cidade foi crescendo em direcção às suas vertentes e às regiões mais afastadas, em especial a região Norte, preservando, contudo o significativo adensamento nas regiões Central e Leste. Esse padrão de crescimento configurará algumas das periferias da cidade, nas quais reside parte expressiva da juventude empobrecida representada na imprensa.

Essa breve caracterização ganha razão quando pensamos que o espaço também se configura como importante elemento na definição das juventudes. Para Hopkins (2011) isso se dá, pois as experiências e acessos aos lugares serão distintos em função da idade. Assim como também os lugares associados a determinados grupos de idade influenciarão aqueles que os utilizam. Acresce-se a essas razões o fato de que o espaço é parte constitutiva da prática desses jovens, sendo, igualmente, elemento que define a condição juvenil em suas múltiplas dimensões. No movimento dialeticamente imbricado, sua juventude se produz na/pela/com a relação que os jovens estabelecem com o espaço. Suas diferentes formas de espacialidade, os usos distintos e desiguais, a maneira como concebem e representam a cidade, os lugares que frequentam e não frequentam, vão compondo a complexa teia de relações que constitui as juventudes. É assim que a experiência do jovem na cidade é elemento fundamental na constituição do sujeito.

\section{METODOLOGIA}

Norteada pelo objetivo de compreender a maneira como a imprensa local contribui na construção de uma representação social sobre os jovens pobres e seus bairros de residência, a metodologia consistiu de duas etapas. A primeira possibilitou apreender qual a 
imagem vinculada pela imprensa local a respeito dos jovens pobres, residentes nos bairros de maior vulnerabilidade social. Para isso, realizou-se a leitura do jornal Tribuna de Minas, impresso diário de maior circulação da cidade. A coleta incluiu o período de janeiro de 2005 a dezembro de 2011. Todas as secções do jornal foram lidas, tendo sido coletadas, no entanto, apenas as notícias em que jovens eram retratados, seja como autores ou vítimas do ocorrido. Posteriormente, as matérias foram agrupadas em categorias conforme o tipo de evento e participação do jovem dando origem a um banco de dados. Os eventos foram nomeados como: assalto, agressão, homicídio e droga. Cabe destacar que esse último evento refere-se a circunstâncias envolvendo consumo e venda de drogas. Por fim, cada evento reúne um conjunto de situações consideradas crime pela legislação brasileira, tais como: agressão física, assalto ou tentativa de assalto, tráfico e consumo de drogas, assassinato e/ou tentativa de homicídio. Fica ainda a ressalva de que os dados coletados são matérias vinculadas na imprensa e não representam necessariamente um incremento no número real de atos violentos e criminosos ocorridos nesses bairros, mas o aumento do interesse da mídia em noticiar esse tipo de fato nessas localidades.

Foi coletado o total de 1731 notícias que resultaram em 1606 eventos. Desse total, 1434 correspondiam a eventos categorizados como homicídio, droga, assalto e agressão. Cabe esclarecer que um evento pode agrupar mais de uma notícia veiculada no impresso (ou seja, o mesmo evento pode ter sido noticiado durante mais de um dia no jornal). Nesse caso, cada matéria vinculada ao mesmo evento foi registrada em mais de uma entrada, sendo indicado, todavia, que se referia a um mesmo evento. Disso resulta a discrepância entre o número total de notícias e o de eventos.

No que respeita ao perfil geral das notícias, tem-se que mais de $90 \%$ referiam-se a eventos associados à violência. Também é importante destacara impossibilidade de traçar um perfil mais detalhado e preciso dos jovens retratados em relação à idade e sexo, já que nem todas as matérias fornecem essas informações. O que é possível dizer é que os jovens retratados eram tanto homens como mulheres e em idades que variavam de 14 a 24 anos. Dentre as matérias que explicitavam o sexo a grande maioria tratava de jovens homens, sendo que esse padrão se repete para todas as categorias de eventos coletados.

Numa segunda etapa foram realizadas entrevistas com jovens estudantes de duas universidades da cidade, bem como numa escola que oferece Educação de Jovens e Adultos (EJA), de maneira que fosse possível avaliar suas formas de uso e apropriação da cidade. $\mathrm{O}$ objetivo foi o de identificar o rebatimento das imagens construídas pela imprensa, relativas à juventude pobre e às práticas espaciais dos jovens estudantes. Ou seja, tendo como perspectiva de análise o cotidiano dos jovens estudantes, buscou-se apreender como suas escolhas relativas aos locais que evitam na cidade são condicionadas e influenciadas pelas representações produzidas e difundidas pela imprensa a respeito dos lugares considerados violentos da cidade, bem como dos sujeitos dessa violência.

A escolha por esses jovens se justificou por estarem ainda em processo de formação e contarem com um conjunto de oportunidades. O que os diferem daqueles comumente retratados na imprensa. Procurou-se também considerar as características de gênero, cor, renda, local de moradia, situação familiar e outras categorias julgadas relevantes no processo de pesquisa e que, de alguma forma, influenciassem o movimento desses jovens 
pela e na cidade. Em 2012 foram entrevistados 48 jovens na faixa de 15 a 24 anos, dos quais 25 homens e 23 mulheres, sendo que $63 \%$ deles declaram possuir algum tipo de renda. Desse número de participantes da pesquisa, $40 \%$ afirmaram ser o salário o principal tipo de rendimento, seguido de bolsa estudantil. A grande concentração de jovens que declarou ter no salário a principal fonte de renda é entendida quando se considera que $49 \%$ dos entrevistados afirmaram trabalhar. Além disso, levando-se em conta a maior concentração de entrevistados na faixa de 21 a 24 anos é previsível que grande parte deles já esteja inserida, de alguma maneira, no mundo do trabalho. Também foi expressiva a importância da mesada como fonte de renda, especialmente entre os jovens de menor faixa etária. Por fim, quanto ao local de residência, o que se registrou foi um padrão de localização na região central, refletindo o próprio padrão de ocupação da cidade. Destaca-se que os bairros componentes dessa região de Juiz de Fora são os que concentram população de maior nível de renda, sendo também os mais dotados de equipamentos públicos e privados.

A imagem exprimida pela imprensa foi confrontada com as escolhas dos jovens estudantes em relação à sua movimentação pela cidade. Portanto, o foco está no desvelamento das formas de apropriação da cidade, tendo como ponto de partida as experiências cotidianas dos jovens na e pela cidade. Tais experiências implicam a escolha quanto à mobilidade que, por seu turno, é entremeada pelas representações sociais da violência (em sua natureza, local de ocorrência e sujeitos), tendo a mídia importante papel na definição dela.

\section{O OUTRO DESIGUAL: IMAGEM E REPRESENTAÇÕES SOBRE OS JOVENS POBRES}

Para Moscovici (2003: 33), estamos frequentemente envoltos por ideias, palavras e imagens que "penetram nossos olhos, nossos ouvidos e nossas mentes" e que vão engendrando as representações de determinado objeto social. Ainda, conforme o autor, essas representações sociais são como códigos do senso comum, tecidos a partir do cotidiano e que participam na construção de certas concepções e visões de mundo que os diferentes sujeitos possuem sobre a realidade. Essas representações seriam sistemas de interpretações que regem os sujeitos com o mundo e com os outros, sendo definidas como "um conjunto de conceitos, frases e explicações originadas na vida diária durante o curso das comunicações interpessoais" (Moscovici, 1978: 75).

Tal interpretação permite concluir que a representação sobre algo sempre se dá a partir da relação com o outro, capaz de produzir uma interação que, para Alves-Mazzotti (2008: 21), cria "universos consensuais", nos quais novas representações são produzidas e comunicadas, transfigurando-se de simples opiniões para "verdadeiras teorias do senso comum, construções esquemáticas que visam dar conta da complexidade do objeto, facilitar a comunicação e orientar condutas".

De modo geral, é possível pensar que as representações sociais se constituem como ideias socializadas, resultantes da vivência coletiva e da forma como cada um inter- 
preta as figuras e imagens socializadas. São, portanto, orientadas para a comunicação e compreensão do contexto social e, manifestam-se como imagens, conceitos, categorias, teorias socialmente elaboradas e compartilhadas. Elas contribuem tanto para a elaboração de uma realidade comum como para a comunicação entre os indivíduos, sendo somente compreendidas quando contextualizadas em termos de suas funções simbólicas e ideológicas. Ou seja, no seu contexto de produção e dos agentes produtores e suas finalidades.

É assim que "os sistemas simbólicos emergem para unificar o imaginário social" e "arquitetam as finalidades e a funcionalidade das instituições e dos processos sociais" (Moraes, 1997: 96). Para Moraes (1997: 97), por meio dos variados imaginários "uma sociedade traduz visões que coexistem, superpõem-se ou excluem-se enquanto forças reguladoras do cotidiano".

\begin{abstract}
"Na atualidade, a mídia tem cada vez mais assumido centralidade no processo de construção do imaginário social, tornando-se um instrumento capaz de produzir "esquemas dominantes de significação e interpretação do mundo" (Coimbra, 2001: 29). Ao influenciar sobre o que pensar e como pensar, a mídia impõe temas e perspectivas. É assim que as imagens veiculadas no tocante à juventude são partícipes na construção do imaginário social sobre os jovens. Especialmente os residentes nas periferias pobres da cidade".
\end{abstract}

São jovens os que mais apareceram nas manchetes e notícias do Jornal Tribuna de Minas. Do total de matérias recolhidas pela pesquisa mais de $95 \%$ associavam esses jovens a eventos de violência. Confirma-se, portanto, a reflexão de Coimbra (2001) sobre a centralidade que a mídia adquire na atualidade ao definir e determinar os temas, comportamentos e modos de compreensão que deverão ser tratados pela sociedade. Esses temas tornam-se, mediante a repetição constante e de sua vinculação cotidiana na imprensa, problemas sobre os quais é preciso se posicionar e criar "soluções". Pela ininterrupta construção de modelos de unidade, de racionalidade, de justiça, de beleza, de cientificidade, os meios de comunicação de massa produzem subjetividades que nos indicam como nos relacionar, como, enfim, ser e viver dentro de uma permanente processo de modelização» (Coimbra, 2001: 30)

Dentre os temas preferidos na mídia para falar dos jovens está a violência. O quadro I a seguir indica a distribuição dos eventos de acordo com suas categorias e tipo de participação do jovem.

Quadro I - Total de eventos, segundo categoria e participação do jovem (2005-2011).

Table I - Total events, according to category and participation of youth (2005-2011).

\begin{tabular}{lccccc}
\hline \multicolumn{5}{c}{ Categorias de eventos } \\
\hline Participação do jovem & Assalto & Homicídio & Agressão & Drogas & Total \\
\hline Autor & 259 & 122 & 115 & 342 & 838 \\
Vitima & 188 & 258 & 150 & 0 & 596 \\
\hline Total & 447 & 380 & 265 & 342 & 1434 \\
\hline \multicolumn{5}{c}{ Fonte: Jornal Tribuna de Minas, 2013 }
\end{tabular}


Uma primeira leitura da tabela aponta que os jovens são mais retratados como autores do evento. Todavia, vale uma ressalva. Os eventos relacionados à droga não possuem registros na categoria vítima, pois tratam apenas da venda e/ou consumo. Sendo assim, se excluídos os eventos envolvendo droga tem-se a inversão, aparecendo os jovens como vítimas mais do que como autores.

Quanto à participação dos jovens em tais matérias nota-se que quando são autores do evento eles estão associados, especialmente, a situações que envolvem drogas, seguidas por assalto e homicídio. Já quando vítimas é o evento homicídio o de maior quantidade de registros.

Ao atentar-se para o total de registros por evento e ano, o que se evidencia é um interesse maior no relato de situações que envolviam jovens e atos considerados violentos. $\mathrm{O}$ quadro II evidencia que de um total de 49 registros em 2005, esse valor passou para 257 no ano de 2011. Aumento considerável, portanto.

Quadro II - Total de eventos segundo categoria e ano de publicação.

Table II - Total events, according to category and year of publication.

\begin{tabular}{lccccccc}
\hline & \multicolumn{7}{c}{ Ano da publicação } \\
\hline Tipo de evento & $\mathbf{2 0 0 5}$ & $\mathbf{2 0 0 6}$ & $\mathbf{2 0 0 7}$ & $\mathbf{2 0 0 8}$ & $\mathbf{2 0 0 9}$ & $\mathbf{2 0 1 0}$ & $\mathbf{2 0 1 1}$ \\
\hline Assalto & 18 & 46 & 53 & 99 & 56 & 94 & 81 \\
Agressão & 17 & 44 & 27 & 64 & 12 & 52 & 49 \\
Homicídio & 6 & 36 & 58 & 57 & 68 & 85 & 70 \\
Drogas & 8 & 29 & 41 & 64 & 55 & 88 & 57 \\
\hline Total & 49 & 155 & 179 & 284 & 191 & 319 & 257 \\
\hline \multicolumn{7}{c}{ Fonte: Jornal Tribuna de Minas, 2013 }
\end{tabular}

Em relação à categoria de evento houve o incremento das notícias relativas a assalto, seguidas de homicídio e droga. Chama especial atenção, no entanto, o fato de que em muitas situações o jornal noticia o consumo ou tráfico de drogas como sendo o "motivo" que explica o evento retratado. A associação direta e simplista entre drogas e violência é repetidamente difundida em muitas das matérias registradas. Homicídio e assalto acabam por se tornar as expressões objectivas dessa relação. Ou seja, é como se as causas das mortes e dos assaltos na cidade estivessem directamente ligadas a um suposto aumento do tráfico de drogas.

Se de um lado, pode-se imaginar que esse aumento acompanha um real incremento da violência na cidade, de outro, contribui para que se forje o imaginário que associa de forma direta os jovens à violência. Imaginário que acompanha a maneira como a própria juventude é muitas vezes concebida tanto pelo senso comum, como nas políticas públicas. Momento transitório que exige atenção e vigilância por parte do mundo adulto, os jovens seriam naturalmente propensos a rompantes violentos. São considerados sujeitos que precisam de constante vigilância, controle e tutela para que não se pervertam ou não se percam no mundo das drogas ou do crime. Por conta dessa imagem da juventude, sobrevive, por exemplo, o discurso que transfere à família e/ou ao indivíduo a culpa pela violência cometida pelo jovem. 
Nas palavras de Guedes (2003: 50):

"A família pobre é frequentemente acusada como responsável pelo destino fracassado de seus filhos, que desde muito cedo são lançados aos perigos das ruas, a falta de escolaridade, aos diversos tipos de exploração, atribuindo à esse abandono a conotação de um ato voluntário praticado por mães insensíveis e por pais descompromissados com o seu papel de proteção."

Cotidianamente a imprensa remete para a sensação (real ou não) de insegurança e medo. O resultado é que a centralidade assumida pela questão da criminalidade e violência nos debates públicos, nas decisões políticas e na vida diária das pessoas é acompanhada pela intensificação do sentimento de medo e pela estigmatização e criminalização de determinados grupos sociais e lugares da cidade.

Ao retratar as manifestações de violência e os jovens como sujeitos dessa violência, a mídia contribui para a construção de estereótipos que consolidam binómios causalistas como: violência e miséria, violência e tráfico, jovem e violência. Ao fazer isso, ela reforça a imagem negativa do jovem pobre urbano. Para Guedes (2003: 56):

"Os jovens pobres são cada vez mais identificados a partir de estereótipos que os enquadram como marginais em potencial atraindo os olhares carregados de preconceitos: do aparato policial que o identifica como "suspeitos", da mídia que reforça essa imagem através de matérias que alardeiam a sua enorme ameaça e da sociedade que deposita nesses jovens a responsabilidade pelo aumento da criminalidade."

A violência, no entanto, somente pode ser compreendida ao ser acionada uma complexa teia de múltiplas determinações. Isso exige, conforme salientado por Sposito e Góes (2013: 13), "a problematização da unificação de uma pluralidade de eventos, circunstâncias e fatores num único conceito, que tem favorecido o encobrimento de relações de poder, ao mesmo tempo em que a violência é representada como um sujeito difuso". Embora fuja ao escopo da discussão deste trabalho, existem alguns elementos que ajudam a compreender o fenômeno da violência. Dentre eles, o sentido de instabilidade que domina a vida atual, decorrente, em grande medida, da inexistência de barreiras à ação do mercado e do capital, que tornam incertas as garantias de emprego e de condições de trabalho e vida. Tal insegurança resulta no enfraquecimento dos laços e das relações interpessoais, produzindo a sensação partilhada por todos de um mundo cada vez mais indeterminado, maleável e competitivo. Sob essa lógica, a diferença se reverte em desigualdade e, o outro passa por completa objetivação de sua humanidade, tornando-se objecto de políticas de segurança pública e/ou mesmo de aniquilação.

Para Ribeiro e Lourenço (2003: 87), há uma racionalização cada vez mais aguda, no sentido de legitimar o descarte dos jovens pobres, que "não se ajustam às molduras simbólicas da juventude e não interessam aos comandos da gestão da economia". Ainda, de acordo com as autoras:

“(...) os processos envolvidos no acesso à idade adulta e, portanto, à construção cultural do envelhecimento, contêm, atualmente, pressões contraditórias quase avassaladoras: por um lado a navegação na incerteza, que constitui a alavanca da fase contemporânea 
do capitalismo, e, de outro, a exigência de adesão a crenças que orientem a relação presente $\rightarrow$ futuro e, portanto, a afirmação num mundo comandado pela competitividade e pelo individualismo" (Ribeiro \& Lourenço, 2003: 87).

Nesse ambiente de instabilidade e insegurança na vida, o aumento do medo do crime torna-se comum ao cotidiano das cidades. Crime e a violência convertem-se em assuntos de destaque e o medo passa a simplificar a leitura sobre o mundo, dividindo-o entre o bem e o mal. É ele que explica o crime e a violência a partir de preconceitos, estereótipos e estigmas e define a existência de um grupo social centrado no tema da violência urbana, objeto do medo e alvo das medidas repressivas.

\section{IV. “LÁ EU NÃO VOU, NÃO!": O MEDO DA CIDADE É O MEDO DO OUTRO}

\section{A perspectiva da mídia}

Assim como não são todos os jovens descritos como perigosos, também não são todos os locais da cidade retratados como violentos e perigosos. A vinculação entre violência e pobreza expressa outra relação comumente concatenada nos registros coletados na imprensa, aquela referente à violência e periferia. Para melhor compreensão dessa relação é preciso considerar que Juiz de Fora se caracteriza por ser uma cidade de significativa concentração de renda, tendo expressivo percentual de população, cujo rendimento é de até um salário mínimo (SM), conforme dados do último censo. Essa concentração também tem sua expressão territorial. Enquanto na região Central estão localizados os bairros considerados mais valorizados, espraiam-se por grande parte do território de Juiz de Fora os bairros de expressiva pobreza, sendo nas regiões Norte e Leste da cidade onde mais se concentram. São também essas as três regiões - Central, Norte e Leste - as mais retratadas no jornal.

Todavia, é preciso refinar a investigação separando as matérias por categorias de evento. Tal movimento permite identificar que para cada tipo de crime há um determinado padrão de localização e uma forma específica de tratamento pelo jornal. Embora o medo da violência perpasse a totalidade da cidade e as matérias estejam fundamentalmente concentradas na região Central, existem aqueles locais considerados potencialmente perigosos e, por isso, devem ser evitados. Há, com isso, uma espécie de regra que determina para cada tipo de ato violento e para cada forma de participação do jovem, um padrão específico de espacialização das matérias.

Ao tomar como referência os tipos de evento, os assaltos foram mais relatados no Centro e na região Norte. Porém, enquanto na região Norte, os jovens eram predominantemente os autores do assalto, na Central, eles eram retratados como vítimas, o mesmo ocorrendo na região Sul. Em ambas, mas em especial na Central, os jovens são descritos como estudantes que ou residiam ou estavam transitando pelas regiões em função do estudo ou da busca pelos serviços existentes. É comum o uso de termos como “jovem", 
"rapaz", "estudante", "transeunte", ao referirem-se aos jovens como vítimas. Enquanto, no caso de serem autores, foram mais comuns palavras como "marginal" "meliante" "indivíduo" e "bandido".

Para os eventos categorizados como agressão, considerando ambas as formas de participação, foi a região Norte, seguida pela Central, as que mais apareceram nas reportagens. Muitas dessas matérias são relativas às brigas de motivação territorial. Nesse contexto, há o confronto entre jovens residentes de bairros considerados rivais. Também é frequente que tais enfrentamentos ocorram na região Central da cidade, considerada neutra pelos jovens. Além dessas notícias, também são comuns as matérias que apresentavam agressões ocorridas nas escolas. Para esse tipo de evento - agressão - autores e vítimas se confundem e são representados fundamentalmente como sendo jovens das periferias, estando mais comumente no papel de vítima do que de autor.

Também os atos envolvendo drogas e homicídios são mais frequentemente relatados nas periferias da cidade, tradicionalmente associadas à imagem de pobreza e habitando o imaginário social como lugares violentos. As matérias relativas à categoria homicídio estão concentradas na Região Norte da cidade, seguida da Leste, sendo maior o número de matérias relatando os jovens como vítimas de homicídio do que autores. A região Leste, de Juiz de Fora, destaca-se como tendo a maior concentração de matérias relativas à droga, seguida pela Norte. No caso do evento drogas, o jovem é apenas o autor.

São as regiões Central, Norte e Leste as que se sobressaem na imprensa local quando se faz alusão a atos violentos. Há, no entanto, que se fazer a distinção necessária entre elas e, em especial, entre as regiões Norte e Leste e a Central. Tal diferenciação permite compreender como o jornal trata e relata cada uma delas ao estipular uma forma de abordagem diferenciada para o Centro da cidade e para as duas outras regiões.

A região Central tem população um pouco maior que 100 mil habitantes, distribuídos em 24 bairros, dos quais a maioria é residencial e considerada valorizada na cidade. Também é nela que se localiza o centro comercial, que reúne as principais atividades comerciais e de serviços, sendo, portanto, a de maior circulação de pessoas e capital em Juiz de Fora.

O mesmo não se pode dizer das regiões Norte e Leste, estando nelas a maior parcela da população pobre da cidade. A região Norte subdivide-se em 63 bairros, com população maior que 76 mil habitantes. A Leste é composta por 34 bairros e, cerca de 85 mil moradores, sendo também caracterizada por uma ocupação antiga e bastante adensada, superada apenas pelo Centro. Seu sítio é íngreme sendo comum a ocupação nas encostas de morros. São nas regiões Norte e Leste que se localizam o maior número de habitações subnormais, classificadas pelo IBGE (2010). Dos 14 aglomerados subnormais definidos por aquele órgão, seis estão na Zona Norte e dois na Leste. Além disso, considerando que a média de pessoas na cidade que recebe até $1 \mathrm{SM}$ é de 22,7\%, 45 regiões urbanas encontram-se acima da média, sendo que, proporcionalmente, é a região Leste da cidade a que mais concentra essa faixa de rendimento.

Ao retratar com maior frequência os eventos ocorridos nessas duas regiões, a imprensa acaba por contribuir para a consolidação de uma imagem de pobreza e violência. Autores, como Caldeira (1984) e Marques e Torres (2005), já apontaram para a 
importância de se reconhecer a diversidade material e simbólica que compõe a vida da/ na periferia. Todavia, ao repetir sistematicamente o binômio pobreza-violência, a imprensa difunde a ideia oposta, a de uma suposta unidade e homogeneidade das áreas periféricas, atribuindo a essas regiões características homogeneizantes, marcadas, especialmente aos homicídios e ao envolvimento com drogas.

Baptista (1999) desperta nossa atenção para a existência de determinados sujeitos sociais que se comportam como "amoladores de faca". Sem rosto e sem personalidade, ocultos sob uma pretensa neutralidade, através de discursos, textos, modos de pensar e de falar, esses sujeitos fragmentam a violência, reduzindo-a a particularidades e a casos individuais, contribuindo para o acirramento das tensões urbanas. Para o autor, os "amoladores de faca" podem ser encontrados entre "profissionais de prestígio" tanto dentro quanto fora da mídia e, produzem a "ingênua e eficaz impressão de uma fala individual e neutra”. A ação de seus discursos, todavia é microscópica e cuidadosa. Esses profissionais, ao criarem perguntas e procurarem dar-lhes resposta, determinam quais os problemas e suas respectivas soluções (Baptista, 1999: 46).

Ao agir como "amoladores de facas", a imprensa participa da construção de uma imagem de violência que se objetiva nessas áreas da cidade, definindo-as como perigosas e, portanto, lugares a serem evitados. Assim a imprensa local legitima e aclama a necessidade de ações que tenham como intenção "reduzir a incidência de crimes violentos (...) e aumentar a sensação de segurança da população", conforme depoimento do comandante geral da Polícia Militar da cidade, quando questionado sobre o incremento de assaltos no Centro da cidade por uma repórter local.

Para as zonas Leste e Norte, as matérias centram-se unicamente em relatar o ato sem apresentar ou cobrar as ações do poder público e/ou da sociedade. Ou seja, a distribuição das matérias por tipo de evento e região na cidade permite perceber que, de uma forma geral, são outorgadas às periferias da cidade a imagem de violenta. Ao enfatizar apenas a violência e as ocorrências policiais, conforme já afirmado, a imprensa acaba homogeneizando esses espaços, simplificando sua vida social e, atribuindo a eles valores e sentidos associados ao crime, à violência e à pobreza.

A mídia faz isso tanto pela repetição quanto pela determinação dos temas e fatos relativos às periferias que podem e devem ser relatados, bem como a forma como eles serão apresentados. Ao serem desconectadas da cidade e ao desconsiderarem os processos socais que lhe originaram e lhe conformaram, as periferias da cidade são vistas como lugares violentos e seus moradores, especialmente quando jovens, como criminosos ou potenciais bandidos.

O que, portanto, permite pensar que o imaginário social, além de uma dimensão política, possui uma forte componente espacial dada pelos significados que são atribuídos aos lugares. Para Castro (1997: 177),

“(...) todo imaginário social pode revelar-se imaginário geográfico. (...), o imaginário reporta-se a espaços, produz uma topografia que lhe é própria e reflete, embora transformado, as relações que o homem estabeleceu com o espaço, onde o passado trouxe suas inscrições, dando assim uma materialidade à memória colectiva”. 


\section{A perspectiva dos jovens estudantes}

Pain (2001) define o medo do crime e da violência como uma gama ampla de respostas emocionais e práticas ao crime e à desordem. Para ela, essa definição enfatiza o impacto das preocupações sobre o crime na vida social cotidiana das pessoas. Além disso, o medo do crime e da violência se constrói socialmente e a partir de diversas identidades sociais, reforçando o fato de que para muitos haveria uma associação entre o medo e determinados lugares na cidade. É assim, que o medo contribui para a imagem negativa de determinadas áreas da cidade e participa nas escolhas dos locais que se evita ir, forjando estigmas que são dados aos lugares e aos sujeitos que neles residem.

Pain e Smith (2008) sinalizam para o fato de que o medo se materializa de diferentes formas. Uma delas alude os efeitos que ele tem sobre a mobilidade, o comportamento e o estilo de vida. É o que se observou entre os estudantes entrevistados na pesquisa. Ao elencarem os lugares da cidade a que evitam ir, apontaram não irem a bairros periféricos, identificados, por eles, como violentos. Um dos entrevistados, morador do bairro São Mateus, na região Central da cidade, é enfático em declarar: "Lá eu não vou, não!". Lá, citado pelo jovem, é um bairro periférico de Juiz de Fora.

Chama atenção, contudo, o fato de que todos os bairros mencionados pelos jovens entrevistados nunca foram visitados por eles, como exemplificam as suas opiniões:

“(...) eu não vou assim em lugares que não seja os que eu conheço, então em nem sei te falar onde eu evito assim, mas eu sei que tem os bairros perigosos, tipo assim, Dom Bosco que eu sei que é perigoso e eu tento evitar passar" (Jovem, homem, 20 anos, morador da região Oeste. Entrevista de campo, 2012).

"Vila Ozanan, Solidariedade, esses assim. Porquê cê olha no jornal é muita violência, é muita gente mexendo com esse negócio de drogas, então por causa dessas coisas mesmo" (Jovem, homem, 22 anos, morador da região Central. Entrevista de campo, 2012).

“(...) se eu fosse evitar eu ia evitar um bairro mais famoso por ser violento. Linhares ou Cidade do Sol, eu posso até estar equivocado no que eu to falando. Só por ouvir falar, mas posso estar equivocado" (Jovem do sexo masculino, 19 anos. Entrevista de campo, 2012).

"Acho que os lugares mais perigosos, que têm mais índices de assalto, e assassinatos, essas coisas a gente procura evitar mesmo" (Jovem, mulher, 22 anos, moradora da região Central. Entrevista de campo, 2012).

"Atrás da minha casa dizem que é muito perigoso, atrás do Bom Pastor, na Vila Olavo Costa, acho que é só lá. Eu conheço muito pouco esses bairros assim” (Jovem, mulher, 22 anos, moradora da região Central. Entrevista de campo, 2012).

Para eles, a ausência de experiência real nesses bairros não é o fator determinante em suas escolhas. Não vão, pois "ouviram falar", ou porque "leram no jornal", ou ainda porque "alguém disse que é muito perigoso". Pedrazzini (2006: 119) pondera que "a qualidade 
da relação entre usuário e seu ambiente é mediada pelo sentimento de insegurança e directamente afetada pela instauração progressiva do perigo". Para esses jovens entrevistados, não pesa, na sua decisão de evitarem determinados bairros, o fato de nunca terem vivido uma experiência violenta neles. O que determina suas escolhas é a percepção de insegurança que, por sua vez, condiciona as práticas adotadas para respondê-la.

A violência representada não necessariamente coincide com a violência real. Nesse movimento de dissociação entre o real e o representado, a mídia tem papel fundamental ao produzir e se apropriar do medo e forjar uma determinada realidade. É assim que, mesmo sem nunca terem ido a esses locais, ou terem vivido alguma experiência violenta, os jovens aceitam com naturalidade as imagens socialmente produzidas sobre as periferias e seus moradores. Os jovens reproduzem a dicotomia entre centro e periferia através das ideias que são transmitidas a eles por outros, que lhe dizem o que é a periferia: violenta e perigosa. Ao naturalizarem essas imagens, acabam por torná-las suas. Eles relatam:

"É, os bairros que eu não conheço e dizem ser mais violentos, eu evito sim. Ah, eu não sei nome, não sei nome, mas os mais afastados do Centro" (Jovem, mulher, 20 anos, moradora da região Sul. Entrevista de campo, Juiz de Fora, 2012).

A sensação de insegurança associada àqueles bairros não surge como uma experiência real, mas como repetição de um medo que é, em grande medida, socialmente (re) produzido. Pain (2001) salienta que o medo do crime cria e reforça a exclusão da vida social e de determinados espaços urbanos. "Ouvir falar", "é o que se lê", "é o que se vê no jornal" foram expressões comuns nas falas dos estudantes para justificar por que determinados locais da cidade seriam perigosos. A frase seguinte exemplifica:

"Santa Rita, Furtado, Olavo Costa, Alguns da Zona Norte, os mais distantes né, Náutico, Igrejinha, a gente acaba evitando. Ah, o motivo é aquele que a gente sempre vê no jornal, né. Confusão" (Jovem, homem, 19 anos, morador da região Central. Entrevista de campo, Juiz de Fora, 2012).

Há, dessa forma, na colocação do jovem, um significativo abismo entre a violência real e a violência representada. Nas palavras de Abramovay e Castro (2006:15):

“(...) nem sempre a violência se fundamenta em crimes e em delitos, mas ela permeia nosso cotidiano, nossas mentes e alma na forma de um sentimento de insegurança. $\mathrm{Ou}$ seja, não necessariamente se fazem necessárias provas, corpos para configurar algo como violência e é neste momento que nos violentamos, alterando gostos, hábitos e prazeres culturais, nos disciplinado por medos. A violência é ressignificada segundo tempos, lugares, relações e percepções, e não se dá somente em atos e práticas materiais."

É o caso dos jovens entrevistados que atribuem valores e significados a determinados bairros da cidade, reproduzindo os estereótipos "da periferia" e a frágil relação entre pobreza e violência, acompanhando e reeditando as imagens geradas de medo difundidas pela imprensa. Uma das entrevistadas alega não ir para Nossa Senhora Aparecida, bairro comumente conhecido como Cidão e localizado na região Leste de Juiz de Fora. O motivo alegado é o o medo: 
“Cidão porque eu já ouvi falar muito também. Então eu tenho medo e nem passo por lá. Ah porque lá tem muito... Dizem que lá é... Não é preconceito, mas é porque eu tenho medo entendeu? Então eu evito." (Jovem, mulher, 23 anos, moradora da região Central. Entrevista de campo, Juiz de Fora, 2012).

O medo da violência, expresso como a razão para evitarem locais na cidade, não é o resultado da experiência e vivência efetiva da violência, mas sim o produto de um imaginário social que determina e define coletivamente os lugares perigosos ou não na cidade, bem como os sujeitos da violência e os modos de pensar e agir diante dela.

Ao mesmo tempo em que relata um aparente caos resultante do aumento crescente da violência, a mídia também procura estabelecer certa ordem (Imbert, 1992). Faz isso indicando os lugares e os sujeitos que devem ser evitados, porque potencialmente são perigosos. Com isso, a imprensa estimula práticas que intensificam a desconfiança em relação ao outro, o esvaziamento dos espaços públicos e a consequente perda da tessitura política.

Sposito e Góes (2013) pontuam a relação entre essas novas práticas citadinas e o futuro da cidade. Para as autoras, o futuro da cidade é cada vez mais condicionado por um presente pautado na representação de uma insegurança urbana e pela desconfiança em relação ao outro. Assim, embora as autoras tratem particularmente das práticas espaciais de moradores residentes em condomínios fechados em cidades paulistas, parece ser possível generalizar essa afirmativa para outras práticas espaciais cotidianas, como as escolhas feitas pelos jovens desta pesquisa ao determinarem os lugares não frequentados.

Por essa razão, são igualmente significativas as paradas e os trajetos desses jovens pela cidade, na medida em que iluminam uma escolha e uma forma de particularizar e valorizar diferencialmente o espaço. Isso porque seus passos, os lugares para onde vão e para onde não vão, os motivos de suas escolhas, seus percursos e as formas de uso da cidade são influenciados pela maneira pela qual a própria imagem da cidade é produzida, tendo a mídia, nesse processo, importante papel.

\section{CONSIDERAÇÕES FINAIS}

Um dos aspectos que se sobressai no tocante ao poder dos meios de comunicação é aquele que se manifesta na produção da culpa e condenação sumária de determinado perfil de indivíduos, através da generalização da suspeição. O que implica, evidentemente, a presunção de culpa. É assim que no processo de construção das representações sociais sobre o jovem pobre e das periferias das cidades a imprensa cria e difunde estereótipos, super dimensionando a violência, ampliando o sentimento de insegurança urbana e contribuindo para a intolerância e criminalização dos jovens, da pobreza e das periferias.

A mídia atua ativamente na produção do medo, associando juventude à violência, apresentando o jovem como o causador da violência. Por sua vez, ela estimula, no imaginário social, a urgente necessidade do aumento da repressão desse grupo. $\mathrm{O}$ medo é ampliado quando se soma à condição juvenil atributos geográficos. Como visto pela coleta de dados, são os jovens moradores das periferias os mais retratados, especialmente quando estão envolvidos em assaltos, homicídio e drogas. 
Resulta desse movimento a fragmentação da cidade em territórios tratados e percebidos como dicotômicos e, em muitos casos, antagônicos: centro e a periferia, o asfalto e a favela, etc. Dicotomias que refletem a separação entre o eu e o outro desigual. O medo da cidade é especialmente o medo do outro. Outro esse que ganha rosto por meio de matérias diariamente veiculadas na imprensa. Outro que reside nos bairros considerados perigosos. A fragmentação da cidade coloca em risco o direito de todos à cidade. Direito que é negado de diferentes formas e intensidades, tanto aqueles jovens rotulados como perigosos, cujos passos devem ser vigiados, controlados e reprimidos, como entre aqueles que também têm sua mobilidade restrita em função da insegurança.

O medo é direcionado tanto aos sujeitos compreendidos como potencialmente perigosos como para os espaços considerados favoráveis à ocorrência de atividades criminais. É assim que o medo do crime e da violência provoca efeitos e tensões excludentes que atingem a vida cotidiana intensificando desigualdades sociais e demonizando os grupos sociais que estariam no fio da navalha do medo (Pain \& Smith, 2008).

A pesquisa conduziu a um entendimento desse processo ao perceber que as escolhas relativas aos lugares da cidade que os jovens estudantes evitam ir são também condicionadas pela sensação de medo e insegurança que domina a vida social. O "medo na cidade" é algo que constitui o próprio imaginário dos jovens entrevistados. Medo que é também encarnado em seus corpos e vai ressignificando seu cotidiano, conduzindo suas práticas socioespaciais na medida em que dividem a cidade em lugares que podem ou não serem visitados. Em suas práticas, portanto, os jovens estudantes reproduzem os estigmas territoriais (Saravi, 2008) produzidos e vinculados pela mídia.

A reprodução de falsas dicotomias como o bem e o mal, o centro e a periferia, naturalizam a desigualdade, expõem preconceitos e multiplicam práticas repressivas e de controle sobre os jovens pobres das periferias urbanas. Mas, tal reprodução também vai enfraquecendo a cidade como espaço público na medida em que rompe os liames sociais que promovem a copresença dos indivíduos. O que se percebeu, portanto, foi a dupla dimensão dessa fragmentação. De um lado, e de forma mais cruel, os jovens pobres vivenciam a negação da cidade em função de sua condição social. Medidas de contenção dos pobres na periferia, de restrição à sua mobilidade na cidade, de repressão e até mesmo o seu extermínio, são exemplos de práticas que negam a cidade aos jovens pobres. De outro, o medo e a insegurança imobilizam outros jovens, aqueles representados nessa pesquisa. Jovens estudantes, de classe média, que pelo temor do desconhecido vão eliminando da cidade os pedaços que consideram estranhos e perigosos (Sarlo, 2009), repetindo os lugares permanentemente retratados pela imprensa. A negação da cidade é a própria supressão da copresença, do estar com o outro diferente, da possibilidade da política como exercício de convivência, coexistência e futuro.

A partir de representações estereotipadas e estigmatizadoras, incansavelmente produzidas e transmitidas pela mídia, se consolida uma sociedade cada vez mais centrada no individualismo que conduz a suspeitarmos do outro e de suas intenções, culpabilizando certos grupos e/ou indivíduos e rotulando os bairros que habitam. A individualização, como forma da sociabilidade moderna, ganha uma tonalidade ainda mais forte num 
cenário de insegurança, em que a apreensão sobre o que poderá vir a acontecer e o temor do outro é cada vez mais banalizada. Para Castel e Haroche (2001), trata-se do enfraquecimento da identidade coletiva, decorrendo na constituição de novas formas de individualidade e na descoletivização, que coloca em xeque o sentido de pertença coletivo dos indivíduos ao forjarem uma nova sociabilidade cada vez mais centrada na individualização. Para os autores, esse indivíduo é fortemente marcado pelo excesso de subjetividade, orientando-se no mundo exclusivamente conforme seus interesses.

$\mathrm{Na}$ exacerbação do individualismo a vida coletiva se enfraquece, condicionando e limitando a possibilidade do uso da cidade como locus da experiência pública e, portanto, política. A vida pública passa a ser substituída pela vida privada, cada vez mais fortificada diante do medo e da insegurança.

Fica, todavia, o desafio de tratar a juventude e a cidade como categorias políticas, superando as leituras que tratam a primeira como abstração e a segunda como objeto. Tal ação obriga pensar a dimensão política da cidade e os jovens enquanto sujeitos. O que, evidentemente, força a refletir como a cidade pode ser espaço de convivência, de troca, de celebração da diferença. Espaço material e simbólico para e na construção de estratégias que projetam um presente e um futuro possível a todos e, em especial, aos jovens.

\section{AGRADECIMENTOS}

Registramos os agradecimentos aos jovens que concordaram em participar dessa pesquisa.

\section{REFERÊNCIAS BIBLIOGRÁFICAS}

Abramovay, M. \& Castro, M. G. (2006). Caleidoscópio das violências nas escolas. Brasília: Missão Criança.

Alves-Mazzotti, A. J. (2008). Representações sociais: aspectos teóricos e aplicações à educação. Revista Múltiplas Leituras, 1 (1), 18-43.

Baptista, L. A. (1999). A atriz, o padre e a psicanalista: os amoladores de faca. In Baptista, L. A. (Org.), A cidade dos sábios. (pp. 45-49). São Paulo: Summus.

Caldeira, T. P. R. (1984). A política dos outros: o cotidiano dos moradores da periferia e o que pensam do poder e dos poderosos. São Paulo: Brasiliense.

Castel, R. \& Haroche, C. (2001). Propriété privée, propriété social, propriété de soi: entretiens sur la construction de l'individu moderne. Paris: Fauard.

Castro, I. E. (1997). Imaginário Político e território: natureza, regionalismo e representação. In Castro, I. E., Gomes, P. C. \& Correa, R. L. (Org.), Explorações Geográficas. (pp. 155-196). São Paulo: Ed. Bertrand Brasil.
Castro, M. G. \& Abramovay, M. (2003). Por um novo paradigma de fazer políticas: políticas de/paral com juventudes. Brasília: UNESCO.

Coimbra, C. (2001). Operação Rio: o mito das classes perigosas. Um estudo sobre a violência urbana, a mídia impressa e os discursos de segurança pública. Niterói: Editora Oficina do Autor e Intertexto.

Guedes, V. G. (2003). Jovens pobres e as vicissitudes da esperança. Rio de Janeiro: UFRJ.

Hopkins, P. (2011). Jovens, masculinidades, religião e raça: novas geografias sociais. In Silva, J. M., Ornat, M. J. \& Chimin Junior, A. B (Org.), Espaço, gênero e masculinidades plurais, (pp. 193-224). Ponta Grossa: Ed. Toda palavra.

Instituto Brasileiro de Geografia e Estatística. (2010). Censo demográfico do Brasil. Disponível em: [consult.og.mar.2015].

Imbert, G. (1992). Los escenarios de la violência. Barcelona: Icaria. 
Marques, E. \& Torres, H. (2005). São Paulo: segregação, pobreza e desigualdades Sociais. São Paulo: Editora SENAC.

Moraes, D. (1997). Notas sobre o imaginário social e hegemonia cultural. Revista Contracampo, 1, 93-104.

Moscovici, S. (1978). A representação social da psicanálise. Rio de Janeiro: Zahar.

Moscovici, S. (2003). Representações sociais: investigações sem psicologia social. Petrópolis: Editora Vozes.

Pain, R. (2001). Gender, race, age and fear in the city. Urban Studies, 38 (5-6), 899-913.

Pain, R. \& Smith, S. J. (2008). Fear: Critical Geopolitics and everyday life. Hampshire: Ashgate.
Pedrazzini, Y. (2006). A violência das cidades. Petrópolis: Vozes.

Ribeiro, A.C.T. \& Lourenço, A. (2003). Marcas do tempo: violência e objetivação da juventude. In Fraga, P. C. P. \& Iulianelli, J. A. S. (Org.), Jovens em tempo real. (pp. 38-53). Rio de Janeiro: DP\&A.

Saravi, G. A. (2008). Mundos aislados: segregación urbana $y$ desigualdad em La Ciudad de México. Santiago do Chile: EURE.

Sarlo, B. (2009). La ciudad vista: mercancias y cultura urbana. Buenos Aires: Siglo Veintiuno.

Sposito, M. E. B. \& Góes, E. M. (2013). Espaços fechados e cidades: insegurança urbana e fragmentação socioespacial. São Paulo: Editora Unesp.

i Este trabalho é fruto da pesquisa desenvolvida no Núcleo de Pesquisa Geografia, Espaço e Ação (NuGea), da Universidade Federal de Juiz de Fora (UFJF) tendo financiamento do CNPq. 